\title{
Cancer screening and COVID-19 pandemic
}

\author{
Rujittika Mungmunpuntipantip ${ }^{*}$ (D), Viroj Wiwanitkit ${ }^{2,3}$ (1)
}

Dear Editor,

We would like to share ideas on article "Dealing with cancer screening in the COVID-19 era." Fagundes et al. concluded that "the decision to keep cancer screening must be discussed and individualized, considering the possibility of new waves of COVID-19" ${ }^{\prime}$. The importance of primary preventive intervention including cancer screening should not be neglected during the COVID-19 pandemic. The practice guidelines might be different in different settings. The coverage rate and cancer detection rate are interesting parameters to be monitored. In our settings, the rates of some cancer screening might be decreased and some might be increased. For example, self-breast examination is increased due to the promotion of this cancer screening practice. Also, the availability of primary care units is still another important factor for promoting cancer screening activity. In the area with maintaining function, cancer screening rate has not been significantly decreased during the COVID-19 outbreak. Risk of delayed screening and cancer detection is recognized during the crisis and it is necessary to have good public health policies to manage $\mathrm{it}^{2}$. Mazidimoradi et al. noted that maintaining the capacity of screening services, lifting of restrictions, and reducing fear in the public are necessary for maintaining successful cancer screening during the COVID-19 pandemic ${ }^{3}$.

\section{AUTHORS" CONTRIBUTIONS}

RM: Conceptualization, Formal Analysis, Validation, Visualization, Writing - original draft, Writing - review \& editing. VW: Conceptualization, Formal Analysis, Supervision, Validation, Visualization, Writing - review \& editing.

\section{REFERENCES}

1. Fagundes TP, Albuquerque RM, Miranda DLP, Landeiro LCG, Ayres GSF, Correia CCE, et al. Dealing with cancer screening in the COVID-19 era. Rev Assoc Med Bras (1992). 2021;67(Suppl 1):8690. https://doi.org/10.1590/1806-9282.67.Suppl1.20200889

2. Garver K. Managing the risk of delayed breast cancer screening versus COVID-19 vaccination associated axillary lymphadenopathy. Acad Radiol. 2021;28(9):1198-9. https:// doi.org/10.1016/j.acra.2021.07.022

3. Mazidimoradi A, Tiznobaik A, Salehiniya H. Impact of the COVID-19 pandemic on colorectal cancer screening: a systematic review. J Gastrointest Cancer. 2021:1-15. https:// doi.org/10.1007/s12029-021-00679-x

\footnotetext{
'Private Academic Consultant - Bangkok, Thailand.

2Joseph Ayo Babalola University - Ikeji-Arakeji, Nigeria.

${ }^{3}$ DY Patil University - Pune, India.

*Corresponding author: rujittika@gmail.com

Conflicts of interest: the authors declare there is no conflicts of interest. Funding: none.

Received on August 19, 2021. Accepted on September 16, 2021.
} 